\title{
Sugar ka Saathi - A Case Study Designing Digital Self- Management Tools for People Living with Diabetes in Pakistan
}

\author{
Kehkashan Zeb ${ }^{1}$, Stephen Lindsay ${ }^{1}$, Suleman Shahid ${ }^{2}$, Waleed Riaz ${ }^{2}$ and Matt Jones ${ }^{1}$ \\ ${ }^{1}$ FIT Lab, Swansea University, Swansea, UK \\ ${ }^{2}$ CS Department, Lahore University of Management Sciences, Lahore, Pakistan
}

\begin{abstract}
This paper presents the results of an iterative participatory process to design a smart self-management tool for less-literate people living with diabetes in Pakistan. Initially, interviews and focus groups with sixty-nine people living with diabetes identified issues that they face when self-managing including uncontrollable factors, lack of diabetes awareness, low-tech mobile phones, and poor internet availability. We developed personas grounded in the scoping results and adjusted our PD approach to focus on more tangible design artefacts before running narrative scoping PD sessions. Working from older, illiterate persona, we designed a phone-line delivered Interactive Voice Response (IVR) system.

We developed a functional IVR Prototype "Sugar ka Saathi" (Diabetes Companion) with input from a group of 4 Pakistan-based healthcare professionals, to act as a design probe in the PD process. We tested the IVR probe with fifty-seven of the original scoping participants which validated the knowledge transferred by the IVR and its acceptability. Invisible design videos were shown to elaborate the IVR and community concept to thirteen participants through two filmed videos using our existing persona characters from the scoping studies, these videos helped to engage older people with diabetes in PD sessions.
\end{abstract}

Keywords: Human Computer Interaction, Participatory Design, Interactive Voice Response.

\section{Diabetes in Pakistan: Challenge and Digital Potential}

People engaging in diabetes management require continuous support, however, in rural Punjab, Pakistan illiteracy and poverty prevent many people from receiving it. Sixty percent of the population lives in rural areas [41] where healthcare facilities are not readily accessible and the prevalence of diabetes both in rural and urban areas is high with, in 2017, over seven million cases recorded amongst a population of 208 million people [21]. People do not have access to important self-management tools for diabetes such as glucose monitoring, exercise tracking, and dietary planning [9,32,22]. These barriers discourage people from trying to take the necessary, routine steps needed to manage their condition and this further aggravates them. 
Fortunately, mobile phones are widespread with $3 \%$ of people owning smartphone and 50\% owning feature phones [20]. Previous research shows that these mobile phones have the potential to act as a platform for healthcare interventions [6, 18]. Even without smart features, mobile devices can deliver information such as help in identification of early diabetes symptoms [3] and management strategies such as diet plans.

However, our scoping work revealed that the mostly older patients living with diabetes are not inclined towards using electronic devices such as smartphones, computers, and laptops [8]. Consequently, in this work, we explored how a technology intervention could help them to improve their lifestyle while working within the constraints of their resistance towards using most electronic devices. The process to do this required us to address two questions: firstly, what techniques could we use to work alongside older people living with diabetes and understand what would and would not be acceptable? Second, what form could an intervention take that would we be possible to deploy given the constraints on literacy and technology?

\section{Literature Review}

Previous work has examined the role of digital tools in the self-management of healthcare conditions in a range of developing contexts addressing a wide range of different diseases. The work highlights a wide range of different barriers that are context dependent and disease dependent.

One of the most comprehensive breakdowns of barriers to treatment in developing contexts looked at treatment of breast cancer in Bangladesh [40]. The work broke down the challenges that people encounter along the lines of: prevent treatment obtainment issues successfully including communication problems in rural areas, scarcity of doctors, gender discrimination, transportation hazards; harmful common beliefs and practices such as herbal medicine reliance; treatment monitoring issues such as long term monitoring abandonment, lack of consistency and fading out behaviors and a range of environmental issues like load shedding, network connectivity and mobile theft [40].

The need to motivate people to engage is widely observed in work local to Pakistan that looks at diabetes management [42] and in culturally related contexts such as India [19]. The studies find that many patients are resigned to their condition and do not believe in the efficacy of self-management approaches so are reluctant to start to engage with them. In this challenge, the family and broader care network are accorded considerable importance as a pathway to help people move beyond their biases and engage in effective self-management [43]. In South Asian countries such as India and Pakistan, households often go beyond the immediate nuclear family such as grandparents and adult siblings and their children, so the family makeup is rich and complex.

With regards to specific self-management approaches, critically reflecting on and analyzing one's experiences is highlighted as vital for diabetes management [43] but criticality can be a difficult skill to impart. 


\subsection{Design}

In healthcare, participation in the design process empowers patients and leads to the design of more successful, useful systems [11] as the end-users needs become prioritized in the design process. Participatory Design (PD) techniques have shown their worth when designing healthcare interventions in developing countries [4] [38], however, projects in economically developing regions show that there are many challenges. For example, the correct identification of stakeholders is not clear at the outset of many of these processes [37] [4]. Even after identification, composing PD groups in ways that encourage engagement from all stakeholders can be difficult [4] because more traditional or rigid social structures inhibit participants. This has led researchers to observe that members of their PD groups do not respect the goal of democratization of the process. In addition, most studies focus on the PD of health systems [36] rather than designing novel or bespoke technology.

Language barriers can also pose a significant challenge as a more diverse collection of languages are often spoken [34]. PD techniques that focus on systems design frequently assume participants literacy, but this is not always (or even often) the case especially in developing countries [35].

\subsection{Interactive Voice-Response}

Our work brought us to consider Interactive Voice Response (IVR) delivered over phone lines. A range of projects have used IVR to address the healthcare needs of illiterate people living in developing contexts. For example, [9] supports people living with HIV or AIDS in India by sending reminders and logging personal wellbeing. [29] uses IVR to provide medication reminders, descriptions of symptoms and tips on self-management for Syrian people living with diabetes. [43] supports community health workers over IVR allowing them to coordinate with one another.

Across these systems we see the capacity for IVR to work with illiterate populations as it requires no reading ability and minimal numeracy to select options on a keypad. The systems work for people who live with low levels of technology access as they can be delivered on mobile or home phones and the technology is low cost. IVR can be used to keep a record of patient's health condition, and the content saving on server side has the potential to make IVRs more secure.

Beyond direct support, an IVR system can keep people with diabetes motivated by interacting with them more frequently than a healthcare professional. Previous community-based radio systems that used IVR to conduct radio sessions, like "Avaaj Otalo" [30] and "Sehat ki Vanni" [29] proved successful in their respective settings and helped community members by delivering information. Because IVR phone lines require no formal tech-literacy beyond making a phone call, they can overcome the barriers identified in technology adoption.

Although IVR systems are marginally more expensive than conventional web-hosting, they can be made sustainable by including advertisements to minimize the financial burden on a host organization [24]. These IVR systems can assist illiterate people 
with diabetes by providing medication reminders, descriptions of symptoms, and tips for self-management to help them with the issues they describe around Monitoring.

IVR is based on content which is usually maintained on server-side and moderators [31] can help to manage this content. Consider the example of community radios where moderators can rate and sort content for IVR radio forums CGNet Swara [27] and Gram Vaani [28] are examples of Community Self-Management tools delivered over IVR systems using health care professionals as moderators.

\section{Scoping Work: Understanding Solution Pathways}

We initially set out to understand the needs and attitudes of people who live with diabetes in rural Pakistan by speaking with a range of people directly. We selected PICTIVE - a technique that relies on involving participants in design activities (using pen and paper) and recording them [23] - because of its similarity to techniques used in some other work [39]. However, the PICTIVE technique did not work with study participants, as we found that demographic factors such as age, literacy level and technical exposure of participants allowed some to express themselves on paper with confidence but most not.

In addition, in this initial work, older, less-literate, females with diabetes were hesitant to show their views on paper, therefore, we interviewed participants so they could be more comfortable sharing their life experiences. As a consequence, we decided to move away from the approach instead conduct semi-structured interviews to understand the challenges they faced mirroring approaches seen in other research [4].

\subsection{Method}

A total of sixty-nine people with diabetes, two diabetes educators, and two doctors who specialize in diabetes treatment participated in the newly organized semi-structured interviews and focus groups. Out of sixty-nine participants, twenty were male and fortynine were female, broadly reflecting the male-female demographic ratio.

We performed one-to-one interviews (typically lasting twenty minutes) with fourteen people with diabetes and sixteen focus groups (typically lasting thirty minutes) with forty-one people with diabetes. Each focus group featured two to four participants and was conducted in home settings.

After getting formal permission from National Hospital of Faisalabad [14] and The Diabetes Institute Pakistan (DIP) of Lahore [13] one-to-one interviews were performed with fourteen people with diabetes and four healthcare professionals (20-30 minutes each).

Most study participants were over fifty years old, had little awareness of technology and had lived with diabetes for between two and eight years with some exceptions including a male participant who had lived with diabetes for thirty years and a female with four months diabetic history.

Language was an issue in these sessions - Urdu is the national language of Pakistan but Punjabi is the local language of Pakistan's province, Punjab. The use of Urdu is 
common amongst mostly literate people however Punjabi is favored amongst illiterate people. In this study, most of the interviews with participants were conducted in Punjabi but interviews with healthcare professionals were conducted in Urdu.

We sought ethics approval from Swansea University College of Science and paid particular attention to how we would obtain informed consent from illiterate participants. Researchers explained the purpose of the study to participants and in the many cases where the participants could not read study information and consent forms, and their consent was recorded along with their signatures.

\subsection{Analysis}

During the analysis stage, we transcribed the recorded videos from scoping activities and translated them from Punjabi or Urdu into English. The process of transcription helped in data familiarization. The transcripts were then analyzed using the Thematic Analysis approach outlined by Braune and Clarke [17] to identify themes within the data. These themes are discussed below with sample quotes from participants.

\section{Uncontrollable Factors Driving Resignation.}

The attitudes of our participants toward their healthcare were resigned due to uncontrollable factors. This set a context for our discussion which the research team had not expected. For example, people with diabetes lived with external stresses beyond their means to control and they criticized both the diabetes educators' way of imparting information and how realistic it was to implement their suggestions. A fifty-seven years old literate female study participant said:

"They told us strategies like do not get stressed and do not think about things that worry you, but how is it possible to not think?"

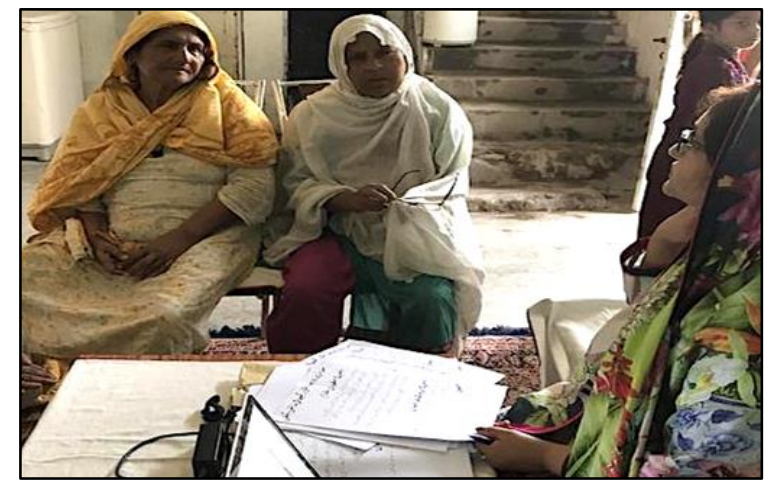

Fig. 1. Participatory design session in Malikpur in home settings

Stress was a detrimental factor in the lives of the people living with diabetes involved in this study. This was particularly the case for women since not only were they responsible for family matters as well as their diabetes; but also, usually lacked a good forum to voice their anxieties. A forty-five years old illiterate female study participant said: 
"Stress affects my glucose level, which is because of several family matters, which are not in my control".

A healthcare professional from DIP, Lahore told that:

"Although there is no cure-all solution for diabetes, one can still keep it under control by remaining motivated and keen to self-manage”.

However, people with diabetes often struggled with motivation and felt that their diabetic condition was beyond their control. For example, a fifty-five years old literate female study participant, living with diabetes for six years, typified the resignation many participants expressed when she said:

"It's God's will that a person is suffering from a disease and only God can cure it, I cannot spend the rest of my life keeping track of my glucose readings".

\section{Adherence to Self-Management Regimes.}

Diabetic patients need to adhere to an altered dietary plan where they eat many smaller meals that can be difficult to maintain, especially given many participants expressing their resignation to living with the condition. For example, a fifty-five years old female participant, enrolled in a Diabetes Education program, stated:

"Diabetes Educators recommended us to take small meals at regular intervals rather than taking heavy meals at a single go, in that way we will feel fuller. But how can you teach the elderly like that? They can use this method for kids but not for the elderly people!"'

As diabetes is a lifetime condition, the behavior of the patient towards self-management can change over time as a sixty years old illiterate female participant said:

"When diagnosed with diabetes, the first two years I cared not to eat sugary things. But since last the 6-7 months, I walk regularly and become careless about food"

Desi medicine (herbal medicine) - plant-based medicine usually used to maintain or improve health - was popular in rural areas, one illiterate female participant said:

"I ate ground Jambolan (fruit), which assisted me in reducing my diabetes medicine from two tablets a day to one tablet a day"

A 60 years old female study participant told us that:

"I had hepatitis; local herbal medicine was effective to cure it".

However - in Guru-Nanak Pura, a relatively wealthier area - ladies explained that they only use medicines from pharmacies and not local herbal medicines.

Glucometers and Bodily Awareness for Diabetes Monitoring.

Issues such as affordability and illiteracy made the use of glucometers less common and instead most study participants relied on perception of their body symptoms to gauge their glucose level as a fifty-five years old illiterate female participant said:

"My body condition and changes tell me about the level of sugar in the body, when it trembles sugar is high, and I experience fatigue and related symptoms when my sugar level is low"

While discussing the regular logging of information, another fifty-two years old literate female participant said: 
"To record these glucose readings using mobile application is a lengthy process, and I do not want to spend the rest of my life using these lengthy processes!"

People with diabetes often complained that monitoring and entering glucose levels was hard and time-consuming. A literate female participant talked about undue stress caused by taking diabetes readings all the time:

"For the last 5-6 years, I've been suffering from diabetes. At the start, I was taking regular readings but then I stopped taking regular readings as this problem is for a lifetime, so what is the use of having this stress all the time? However, at times when I do not feel well, I take the glucose reading to know the cause"

This approach, though palatable to many participants, undermines the medically correct monitoring process with a glucometer. However, the motivation to take readings did vary from person to person, for example, another male patient reported:

"I check glucose reading 2 times daily fasting and during the day for 11-12 years since the problem began."

A sixty-two years old female study participant told us she monitors her condition and if she feels her glucose level is high then she takes two tablets instead of one which shows the general tendency of PWLD towards self-medication.

\section{Awareness and Disregard of Self-Management Techniques.}

Diet management is the key to keep glucose levels under control as a diabetes doctor in the DIP mentioned: "Diabetes management education is more important than medicine". A Diabetes educator told us that:

"The role of diabetes educators rises from the fact that for a diabetes patient, regular self-management of disease is crucial"

Another diabetes educator in the National Hospital of Faisalabad emphasized that:

"A patient rarely understands their condition and so they rely on doctor's medicine only, although the use of medicine is only one factor for controlling the condition"

However, when questioned about their knowledge of diabetes, 55 years old literate female participant said:

"A person suffering from disease knows how to take care of his condition within a few days of having that condition."

On the question of eating habits 60 years old illiterate female study participant said:

"Rich people can answer such questions as what you eat. We just eat chapatti and drink water and do not afford to eat fruit".

These contrasting views highlighted a gulf in understanding between the healthcare professionals' treatment approaches and the routines patients were willing to undertake. Lack of information about diabetes and its associated symptoms was a hurdle for people with diabetes especially at the time of onset and early period of the condition as many participants told us about being diagnosed after experiencing worst symptoms:

"My diabetes started with the frequent need to urinate, even I was unconscious for three days with the glucose level as high as 600"

This reinforces the need for the Pakistani illiterate population to have information about what diabetes is, how it starts, what the preventive measures are to avoid the elevated glucose levels even before diabetes is diagnosed to avoid complications. 


\section{Technology Adoption in Rural and Urban Groups.}

Use of technology to help self-manage diabetes was varied. Amongst less literate study participants who typically lived in less well-resourced settings it was lower, however, literate middle-class participants used computers, laptops, and smartphones, especially the younger one. However, the majority of participants were older, less inclined towards technology and had limited resources, a female participant who came to DIP Lahore from a rural area for a check-up said:

"I do not use a mobile phone; do not even know how to receive the call"

Another study participant from 75 Chak told us that:

"I do not use the phone often and only listen to the received phone call"

In particular, the interviews highlighted that less literate people with diabetes living in rural areas do not use mobile phones with internet access. However, in DIP, doctors and people with diabetes showed an interest in using mobile applications as they were using the WhatsApp messaging service to communicate with each other. A few patients had access to mobile phones with the internet as a 35 years old literate female patient commented:

"I use a mobile phone often with internet availability, I can use different applications like WhatsApp, I am in contact with the doctor on the mobile phone about my current condition and I seek advice from him and will definitely use mobile phone applications to track my condition."

\section{Co-Morbidity.}

Many of the study participants have different coexisting conditions, such as diabetes, hepatitis, muscular pains, stroke, heart issues as a study participant told:

"Due to high sugar and blood pressure I had stoke".

Many people with diabetes reported eyesight issues which affect their seeing ability, due to high glucose level. Some of them get their eyesight checked while others do not get it checked due to affordability. Other issues highlighted in interviews were, hearing issue thus required us to speak loudly. Hepatitis is found widespread especially in villages, 75 Chak, 76 Chak, and 80 Chak.

\subsection{User-Centered Study: Extracting Personas from Scoping study}

The scoping study uncovered different user groups, and this led us to develop personas to illustrate them. These personas give us greater insight into needs and wants of our study participants, which differ due to education levels, age, and gender. 


\begin{tabular}{|c|c|c|}
\hline PERSONA & DETAILS & GOALS \\
\hline Liaquat $\mathrm{H}$ & $\begin{array}{l}\text { Diabetes Patient for } 12 \text { years } \\
\text { Age: } 57 \\
\text { Literate } \\
\text { Profession: Manager } \\
\text { Marital Status: Married } \\
\text { Residence: Faisalabad }\end{array}$ & $\begin{array}{l}\text { He often uses Internet-based appli- } \\
\text { cations on the computer but less of- } \\
\text { ten on the mobile phone. He tries to } \\
\text { maintain his diabetes well with food } \\
\text { and exercise as recommended by the } \\
\text { doctor, but adherence is an issue. }\end{array}$ \\
\hline Anees 1 & $\begin{array}{l}\text { Diabetes Educator } \\
\text { Age: } 25 \\
\text { Literate } \\
\text { Profession: Diabetes Educator } \\
\text { Marital Status: Single } \\
\text { Residence: Faisalabad }\end{array}$ & $\begin{array}{l}\text { He is usually in contact with illit- } \\
\text { erate people with diabetes having } \\
\text { limited resources. He educates them } \\
\text { to create diabetes awareness. He is } \\
\text { available through NGO only in few } \\
\text { hospitals and clinics. Mostly people } \\
\text { with diabetes do not have direct ac- } \\
\text { cess to him. }\end{array}$ \\
\hline & $\begin{array}{l}\text { Diabetes Patient for } 5 \text { years } \\
\text { Age: } 55 \\
\text { Literate } \\
\text { Profession: Teacher } \\
\text { Marital Status: Married } \\
\text { Residence: Lahore }\end{array}$ & $\begin{array}{l}\text { She is less interested in the use of } \\
\text { mobile phone and often use it for lis- } \\
\text { tening to calls. She is knowledgea- } \\
\text { ble about diabetes care. }\end{array}$ \\
\hline Mukhtraan Bi & $\begin{array}{l}\text { Diabetes Patient for } 17 \text { years. } \\
\text { Age: } 70 \text { years } \\
\text { Illiterate } \\
\text { Profession: House Keeper } \\
\text { Marital Status: Widowed } \\
\text { Faisalabad }\end{array}$ & $\begin{array}{l}\text { She is struggling financially. She } \\
\text { does not have direct access to diabe- } \\
\text { tes related knowledge other than } \\
\text { doctor. She is willing to listen to a } \\
\text { helpline. She uses the phone for re- } \\
\text { ceiving a call. }\end{array}$ \\
\hline
\end{tabular}

Table 1. Personas based on Scoping Study.

\section{$4 \quad$ Participatory Design}

Because we found our participants significantly better in communicating verbally than through reading or writing, we selected a range of techniques to fit into what we thought 
of as a verbal design approach - one which generated design artefacts and feedback that was primarily verbal. This meant using a set of approaches that emphasize verbal communication as opposed to emphasizing written notes.

When the research team discussed the first stage of our work, our reflections suggested that many of our study participants' beliefs about their own self-efficacy affected the degree of engagement we could get when working with them. PD depends upon genuine interaction between researchers and the participants and our belief entering this process was that patients' stories about their lived experiences should inform and inspire our work as researchers as we need access to the insights that only they hold. Our semi-structured interviews gained useful insights and presenting PD based IVR probes also garnered engagement but the follow-up activities we planned were less successful.

Our interviews also showed us that the people with diabetes were eager to share their personal experiences and tell us stories so narrative scoping techniques were selected. While stories can be defined as informal and subjective accounts of personal experience, narrative accounts are more formal and structured [1]. To exploit this, we used 'Persona character development' as the basis for collecting these accounts of personal experiences of our study participants and formulating new ideas in relation to the persona created based on our initial scoping (see Table 1). Therefore, in place of tangible, co-created artefacts of the design process, personas were used to capture the results of the storytelling [15] in the Narrative Scoping work.

We also encountered issues stemming from a lack of willingness by some participants to speak up about their problems. This echoes findings from previous work [4] and, in this case, we believed that these issues arose from social norms that typically expect younger or female members of a group to show deference by remaining quiet. We addressed this by conducting PD exercises in one-to-one settings or with small groups of similar participants comfortable with each other already, either being friends where we could recruit them in groups or at least drawing groups from similar demographics such as a group of all older women. This decision emphasized the importance of the verbal elements of the design process and tried to ensure that everyone in a group could speak more freely.

\subsection{PD Session Using Narrative Scoping.}

Four PD sessions were conducted with seventeen people with diabetes from Ashraf town, Malikpur. The participants were recruited through snowballing using local connections; 9 people with diabetes had already been involved in initial scoping. Four participants were male, and rest were female.

The narrative scoping sessions were divided into two parts: 1) Narrative interview session acting as an icebreaker; and 2) Personas of "Liaquat Hussain" and "Mukhtaraan Bibi" used for 'Persona Character Development'. While discussing the capability of using technology, participants agreed that an older female persona would benefit from the use of IVR technology; however, a middle-aged male Persona has access to a smartphone and will be happy to use smart-phone based solution for diabetes management. 
We initially chose the "Mukhtaraan Bibi" persona due to its greater number in this study. Overall in persona-based narrative scoping sessions participants agreed that: "If she receives a call, she can listen to it, but it's difficult that she calls by herself'. The psychological help and reassurance "Mukhtaraan Bibi" will get from this helpline will help her in keeping her better motivated for managing her diabetic condition.

\section{Exploring the Potential of Interactive Voice Response}

The user scoping study showed in rural areas most participants had not used IVR. Therefore, "Sugar ka Saathi" was built to study use cases, usability, and act as a design prompt. A functional IVR Prototype was designed and developed with input from a group of 4 Pakistan-based healthcare professionals. Table 2 shows how themes from the initial scoping were responded to in the design of the system. This prototype acted as an IVR Design Probe and was deployed with 57 of the original scoping participants after creating their user profile on the IVR system. This validated the acceptability of IVR technology and also revealed people living with diabetes's reliance upon their wider community.

\begin{tabular}{|l|l|}
\hline \multicolumn{1}{|c|}{ Themes } & \multicolumn{1}{c|}{ Potential IVR based responses } \\
\hline Awareness of Diabetes & $\begin{array}{l}\text { Persona Mapped to the IVR System present diabetes Infor- } \\
\text { mation verified by diabetes doctors. }\end{array}$ \\
\hline Adherence & $\begin{array}{l}\text { Medicine reminders; Encouraging feedback if the recorded } \\
\text { glucose level seems appropriate; Constructive feedback if } \\
\text { the recorded glucose level is higher than normal. }\end{array}$ \\
\hline Monitoring & $\begin{array}{l}\text { Daily reminders from the system to enter your glucose read- } \\
\text { ing if it is not being entered for a user that day; If a glucose } \\
\text { reading has not been entered in seven days motivational } \\
\text { messages from the system. }\end{array}$ \\
\hline Co Morbidity & $\begin{array}{l}\text { Present information on different diseases; User profiling } \\
\text { and recommender algorithm to present this information ac- } \\
\text { cording to user's customized needs. }\end{array}$ \\
\hline Struggle with Diabetes & $\begin{array}{l}\text { IVR System can incorporate a community Radio Program } \\
\text { to help people by listening to problems and allowing re- } \\
\text { sponses by experts; Questions and answer forum for offline } \\
\text { use; Social Network where people with diabetes interact } \\
\text { with peers. }\end{array}$ \\
\hline
\end{tabular}

Table 2. Ideas for IVR based on different themes taken from the initial scoping.

\subsection{IVR Probe Design and Development}

The prototype of Sugar ka Saathi was designed to create an awareness of diabetes management amongst less literate study participants. The persona of diabetes educator "Anees Khan" was used to deliver information on the IVR system. The information to 
be presented on the IVR system was based on existing websites validated by healthcare professionals in National Hospital Faisalabad (see feedback in Fig 2.).

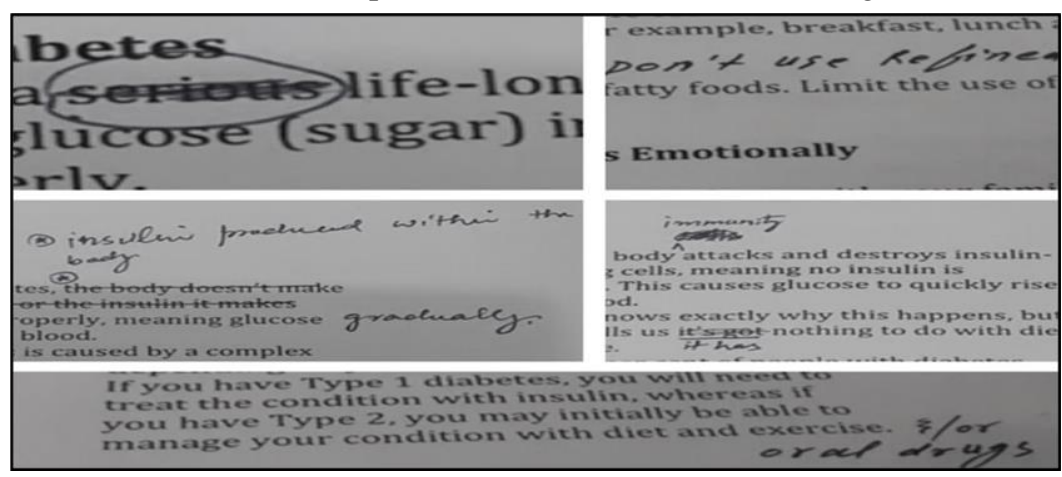

Fig. 2. Doctor's feedback on "Sugar Ka Saathi” Content.

The next stage is to convert the information into a branching flowchart to base the IVR calls off (an overview is shown below in Fig. 3.). All audio prompts were translated and recorded into both Punjabi and Urdu languages using good voice quality to ensure system comprehensibility.

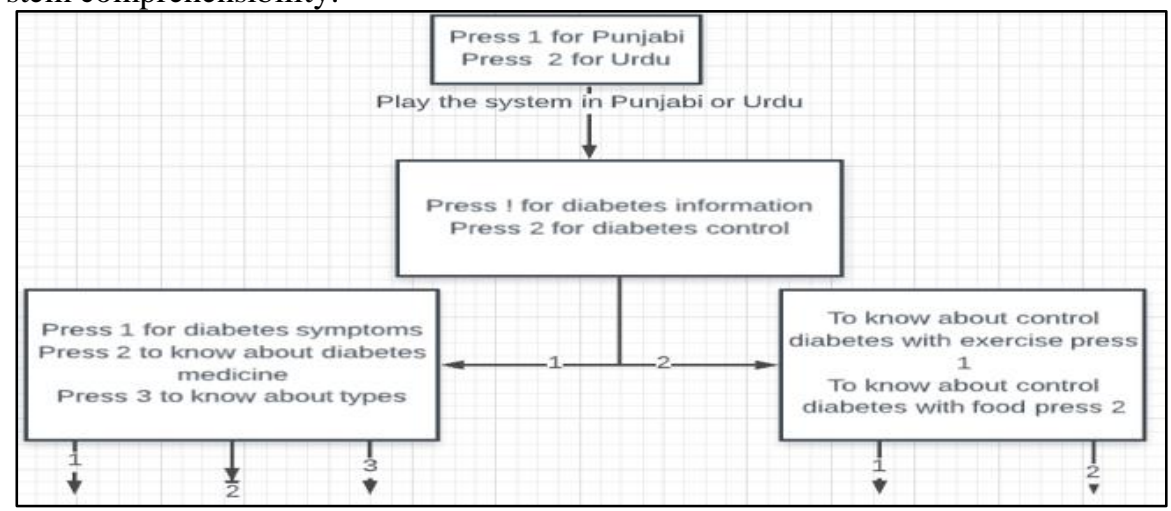

Fig. 3. Flowchart For "Sugar Ka Saathi” Development

"Sugar Ka Saathi" was built on Asterisk VOIP (Voice over Internet Protocol) platform and was developed using PERL Asterisk Gateway Interface (AGI). A MySQL server stores a system log. The telephone communication between the asterisk server and user was done over SIP (Session Initiation Protocol).

The maximum depth among all the submenus in "Sugar Ka Saathi" is four levels and the maximum width is three for the main menu while most of the other sub-menus have a maximum width of two in line with previous work [33]. There are two types of audio response in "Sugar Ka Saathi": navigational prompts at nodes and informational prompts at leaves. On average, the prompt length is 15 seconds and the maximum length is 25 seconds. At any sub-menu, the user has the option to navigate back to the previous menu or to end the call. If the user doesn't enter input against a prompt, "Sugar 
Ka Saathi" waits for a few seconds and repeats that prompt. It also notifies the user of a wrong input at any stage and repeats the prompt.

\section{2 "Sugar ka Saathi" User Testing}

We worked with a user group ranging from 35 to 70 years old. All users spoke Punjabi and understood numerals, but only 3 of the users could read written Urdu. After the creation of the user profile in the system, all study participants were given a briefing that explains the "Sugar Ka Saathi" functions and how to use them. After that users completed tasks:

1. Retrieve basic information about diabetes.

2. Navigate back to the main menu from a sub-menu.

3. Find out how they can manage or control diabetes.

Study Participants gave feedback and suggestions and later informal discussion help to get more in-depth feedback about the "Sugar Ka Saathi" clarifying the design.

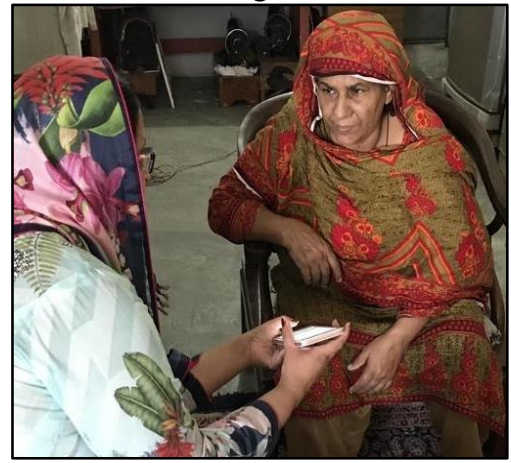

Fig. 4. Researcher showing Demo of IVR in Participatory Design Sessions in Faisalabad.

Users were interested in the system because it provided useful and relevant information regarding diabetes management. Existing mobile owners were confident using the IVR on their own and were relatively successful in interpreting and using the system. However, infrequent mobile users required help to adapt to the system and those with good levels of literacy were more confident in using the system. Some participants inquired about the "Sugar Ka Saathi" (helpline) number so they could call from their own mobile phones which further supported IVR's potential to become a viable solution to serve illiterate or semi-literate people.

Initially, the participants were hesitant in using the system but, after a short briefing on the use and information that was disseminated through it, they gained confidence and found it useful. Each study participant was given a set of tasks during the evaluation. Twenty out of fifty-seven participants could comfortably complete their tasks with no prompt repetitions. Ten participants had better information retrieval times than the rest because of prior experience with the telephone helpline experience. The rest of the participants completed their tasks with a single prompt repetition except for seven users who needed three repetitions of the prompt. 
Users were successful in comprehending both navigational and informational responses although only five users had prior experience with an IVR system. Users waited for responses to repeat for their selection if they could not understand it for the first time which showed a quick grasp of the IVR system after the initial explanation about the repetition functionality. Some users would wait for the prompt to the end before pressing the button while others would press immediately after hearing the option of their choice. Some infrequent mobile users did not understand the prompt during their first call. Something confused them about the functioning of the IVR System and therefore required repetition to understand the navigational responses. Ten users could not complete their tasks.

The semi-structured interviews after the tasks revealed despite understanding the navigational responses the first time, some participants were allowing them to repeat because of a lack of confidence in their own ability to use the system and most of the participants could quickly press the correct selection before the responses completed. In contrast, they repeated informational responses when giving relatively longer (20-25 seconds) ones showing that these longer responses were difficult to grasp in one listening. Upon asking one participant about listening twice to healthy eating information, she said:

"The information was interesting and for remembering this information I listened to it twice"

In the semi-structured interviews, users suggested that the navigational responses in the IVR system were clear, but each repetition helped them become more confident they had understood. There were two instances where the user had pressed the wrong option, unintentionally, for example, pressing two buttons at the same time. On both occasions, they could navigate back to the upper-level menu.

"Voice quality of IVR prompts is good, and I could easily understand them".

When given the chance to navigate the IVR probe, people with diabetes wished to inquire about topics of particular interest, for example, diet management was one of the favorite topics as most of the participants reported that they faced difficulties in managing the glucose levels. The knowledge acquired from other information sources such as doctors was insufficient in the effective management of diabetes. IVR probe users found the exercises and healthy eating tips useful.

During feedback interviews, some participants showed the desire to get information for their personal problems.

"What if I can get customized information regarding my problem".

Research shows that an IVR system can have many functions such as medicine reminder, glucose reading reminder and motivating feedback from the system based on the weekly reading.

Affordability of IVR was an issue as study participants were not ready to bear the cost and mentioned:

"I want the system to be free (Mufat), as I am hardly meeting both ends and cannot afford IVR call".

Since the system was unaffordable by many study participants, advertisements by system is proposed to make IVR sustainable [24]. Most participants have agreed to use this system and provided their phone numbers showing the willingness to receive the 
call from the IVR System. The desire to use helpline again, confirmed us that users like it as this saying:

"I will love to listen to IVR system call again".

Therefore, a more generalized IVR system that considers different diseases and provides information for them simultaneously has a greater likelihood to benefit the patient. Some of our users want to seek knowledge from the system, one semi-literate user said:

"The information provided by this helpline is basic, this system will be beneficial if it has more information."

Another illiterate 60 years old IVR design probe user gives the suggestion:

"What if I can ask questions of my choice and get answers for them?"

One issue found during the use of the IVR probe was the inability of the users to dial numbers, due to eyesight issue, related to their high glucose level. This inability to dial numbers would lead users to seek the help of peers such as the family, for making phone calls and a few people with diabetes mentioned in the study the need to be able to delegate their work:

"Please explain the system to my son or daughter".

\subsection{Developing our View Point}

Looking at user engagement with IVR and desire to get more and customized information from the system, we choose the recommender algorithm [33] and user profiling [7] as potential technologies. Our study participants repeatedly mention the desire to get more information from the system. However, navigating a large amount of information in IVR is not possible with conventional information hierarchy. Therefore, a user profile maintained in the system based on user preferences will later help the intelligent system to give appropriate knowledge to people with diabetes. This intelligent system can address the varied information needs of our study participants such as comorbidity, by keeping track of information, which is already presented and by tracking the new information, users are presented with, based on their profile.

\section{Understanding the Potential for Community IVR In Diabetes Management}

The community element is very important for the use of any technology platform with our illiterate and older participants as, in IVR probe testing, many participants reported that they will seek the help of their children while interacting with an IVR system, because of eyesight or literacy issues. Reliance on peers apart from the close-knit family system is also clear from the user study, as in 75 Chak, participants relied on each other's knowledge and ability to manage the disease, it becomes clear when 40 years old illiterate female participant told:

"I will seek the help of Baji (elder peer participant) to seek information from the IVR". 
This shows not only participants hesitation to use technology but also reliance on peers. People with diabetes often require external motivation and support to help them self-manage their activities and diet [32] and community can play an important role in teaching and motivating them [5]. Community-based healthcare systems like 'Patients Like Me' [16] encourage better self-management. However, these approaches are not accessible to illiterate study participants because of their requirement to know how to read and write.

There is an opportunity for the community model to help motivate people with diabetes to adapt to a healthy lifestyle [29]. Changing a person's attitude towards diabetes management is not possible with technology alone, but it requires a holistic role played by the community, technology, and a person's motivation together to take better care of their diabetic condition. The community can act as a stimulating agent, to serve that purpose and technology can play a vital role by connecting the community to increase diabetes awareness.

Broadly, community self-management, whether realized through the medium of digital technologies or social approaches, can be divided into "Peer Self-Management" and "Community Self-Management". In Community Self-Management, all stakeholders collaborate and share information to address an issue, an example would be an IVR question-answer forum. In Peer self-management, 2-3 patients work as a group to help each other to keep their glucose level on track, the approach is already seen when people managing their own cases of diabetes take the time to help newly diagnosed people with diabetes to manage their condition [14].

The use of a moderator is vital as a health care professional acting as a moderator to guide discussions can make the system more trustworthy. Community Self-Management (sometimes called community moderation) is another option which reduces the need to use a moderator such as the Sangeet Swara project in which community rates every post which helps in moderation [26]. Although less resource intensive to run, the validity of healthcare information shared in peer-self management moderated forums can be questionable as the healthcare professional opinion is crucial when developing a large-scale system.

\subsection{PD Workshop using Invisible Design.}

Invisible Design [25] is a technique for generating ideas with study participants using ambiguous films in which characters discuss technology use without directly showing technology. There were total 13 people with diabetes who took part in 1-1 PD sessions, out of 13 participants, 2 were male and 11 were female. These 1-1 PD sessions were conducted in locations of "75 Chak", and "Ashraf town Malikpur". After participants used the IVR based design probe for 15-20 minutes navigating through various features such as basic information about how to manage diabetes, they saw two videos based on the Invisible Design approach which helped to generate ideas with PD workshop participants focusing on community-based IVR. We showed the filmed scenario using the personas of 'Diabetes Doctor' and 'Diabetes Patient' as shown below, where they discussed the use of Community IVR System in three minutes long movie. Participants 
were quick in grasping the concept behind Community based IVR. They showed enthusiasm using a communal application where they could listen to other people's ideas and share their own insights. We saw that our less-literate participants responded to Invisible Design technique as they know the IVR concept using design Probe. This makes IVR system discussion in invisible design video easy to imagine. Overall it can be concluded that PD techniques based on verbal communication, either verbal discussion or showing video has the potential to engage illiterate participants.

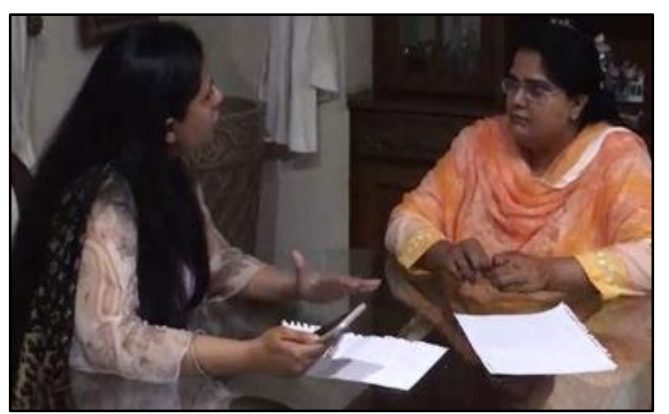

Fig. 5. Invisible Design video with a doctor telling patient about the use of IVR technology.

\section{Discussion}

\subsection{Methodological Challenges}

Since a majority of our participants were reluctant to use conventional PD techniques to design the system itself, we switched over to Narrative Scoping work and used Invisible Design in our workshops. While PD techniques that showed different visual options to our semi-literate participants resulted in greater degrees of engagement and enthusiasm as compared to more free-form ideation; they also restricted the design space and did not reflect the original aspirations of PD. Although some issues we encountered have been reported in other work conducted in other contexts, the specific set of issues we encountered were unique to the Pakistani context we were working at.

\subsection{Pragmatic challenges}

The role of government in the healthcare sector is minimal and expenses are borne solely by the patients in Pakistan. The quality of healthcare facilities in the private and public sector are not comparable. As a result, those who cannot afford the best facilities are left with inadequate resources. Since decent facilities are a by-product of urbanization, they are usually relegated to cities, leaving the rural citizens deprived.

Creating a platform-independent solution that is compatible with all the different types of mobile phone models present in Pakistan is difficult. People in rural areas often rely on older Nokia mobile phones due to their affordability and suitability for their use while smartphones are usually more popular in urban areas though still not widespread. 


\subsection{Attitudes and beliefs}

The PD process has many needs such as participants should be able to convey their viewpoint as their literacy level influences the process. Illiterate PD participants who cannot understand the textual interface may find it difficult to accept the technology introduced with a smartphone. However, research [41] showed the less literate participants can understand the pictures with voice-overs in smartphone applications. In this research when we produced more concrete IVR prototypes and showed them to people with diabetes it resulted in increased engagement levels in the concept of invisible design video after giving them the demo of IVR prototype

\section{Conclusion and Future Directions}

Our initial thinking revolved around a user-driven approach because of the realization that people with diabetes requirements are important and accounting them. The research uncovers the behavior towards technological intervention amongst the less literate people with diabetes through an IVR system design probe that disseminates information for diabetes management.

We plan to extend this project by doing full scale deployment of this IVR system using server so that people with diabetes can use in their home settings. We will incorporate new features based on the user study analysis such as to design and develop a scalable system to give information dynamically, including the option for co-morbid diseases in this system, developing a healthcare Social Network system over IVR to address community support for people with diabetes in managing diabetes. Diabetes based IVR could be a good starting point to empower people with diabetes in Pakistan and this has potential to serve as a stepping stone towards the design of a powerful tool that can educate the rural community about healthcare strategies.

\section{Acknowledgement}

Cherish-De support for this project helped to make this study a reality, we hope to deploy a fully functional helpline after participatory contribution from users.

\section{References}

1. East L, Jackson D, O’Brien L, Peters K. Storytelling: an approach that can help to develop resilience. Nurse researcher. 2010 Apr 1;17(3).

2. Joshi A, Rane M, Roy D, Emmadi N, Srinivasan P, Kumarasamy N, Pujari S, Solomon D, Rodrigues R, Saple DG, Sen K. Supporting treatment of people living with HIV/AIDS in resource limited settings with IVRs. In Proceedings of the SIGCHI Conference on Human Factors in Computing Systems 2014 Apr 26 (pp. 1595-1604). ACM

3. Agency for Healthcare Research and Quality (AHRQ). Improving Care for Diabetes Patients through Intensive Therapy and a Team Approach. November 2001. Last Accessed5th January 5, 2018 from https://archive.ahrq.gov/research/findings/factsheets/diabetes/diabria/diabria.pdf. 
4. Hussain S, Sanders EB, Steinert M. Participatory design with marginalized people in developing countries: Challenges and opportunities experienced in a field study in Cambodia. International Journal of Design. 2012 Aug 1;6(2).

5. Kumar N, Perrier T, Desmond M, Israel-Ballard K, Kumar V, Mahapatra S, Mishra A, Agarwal S, Gandhi R, Lal P, Anderson R. Projecting health: community-led video education for maternal health. In Proceedings of the Seventh International Conference on Information and Communication Technologies and Development 2015 May 15 (p. 17). ACM.

6. Mamykina L, Miller AD, Mynatt ED, Greenblatt D. Constructing identities through storytelling in diabetes management. In Proceedings of the SIGCHI Conference on Human Factors in Computing Systems 2010 Apr 10 (pp. 1203-1212). ACM.

7. Middleton SE, Shadbolt NR, De Roure DC. Ontological user profiling in recommender systems. ACM Transactions on Information Systems (TOIS). 2004 Jan 1;22(1):54-88.

8. Vaportzis E, Giatsi Clausen M, Gow AJ. Older adults perceptions of technology and barriers to interacting with tablet computers: A focus group study. Frontiers in psychology. 2017 Oct 4;8:1687.

9. Mamykina L, Mynatt ED, Kaufman DR. Investigating health management practices of individuals with diabetes. In Proceedings of the SIGCHI conference on Human Factors in computing systems 2006 Apr 22 (pp. 927-936). ACM.

10. Triantafyllakos G, Palaigeorgiou G, Tsoukalas IA. Fictional characters in participatory design sessions: Introducing the "design alter egos" technique. Interacting with Computers. 2010 May;22(3):165-75.

11. Chapman L. Design for Chronic Illness: Exploring Service Systems \& New Technologies for Patients with Type 2 Diabetes.

12. Simonsen J, Robertson T, editors. Routledge international handbook of participatory design. Routledge; 2012 Oct 12.

13. Diabetic's Institute Pakistan website. Last accessed 29th Aug 2017 from http://www.diabetespakistan.com/lahoremain.php

14. National Hospital Faisalabad Website Last Accessed: 30th Aug 2017 from http://www.nationalhospital.enic.pk/.

15. Bidwell NJ, Reitmaier T, Marsden G, Hansen S. Designing with mobile digital storytelling in rural Africa. In Proceedings of the SIGCHI Conference on Human Factors in Computing Systems 2010 Apr 10 (pp. 1593-1602). ACM.

16. Patients Like me. Last accessed: 17th Sept 2017 from https://www.patientslikeme.com/.

17. Braun V, Clarke V. Using thematic analysis in psychology. Qualitative research in psychology. 2006 Jan 1;3(2):77-101.

18. Muller MJ. Participatory design: the third space in HCI. Human-computer interaction: Development process. 2003;4235:165-85.

19. Rafique, G. and Shaikh, F., 2006. Identifying needs and barriers to diabetes education in patients with diabetes. JOURNAL-PAKISTAN MEDICAL ASSOCIATION, 56(8), p.347.

20. The rise of mobile and social media in Pakistan. Retrieved 22nd Jan 2019 from http://www.dawn.com/news/1142701.

21. Demographics of Pakistan. Last accessed: 17th Jan 2019 from https://en.wikipedia.org/wiki/Demographics_of_Pakistan.

22. Hinder S, Greenhalgh T. " This does my head in". Ethnographic study of self-management by people with diabetes. BMC health services research. 2012 Dec;12(1):83.

23. Muller MJ. PICTIVE - an exploration in participatory design. In Proceedings of the SIGCHI conference on Human factors in computing systems 1991 Apr 27 (pp. 225-231). ACM.

24. Kharal A, Naseem M, Ahmad SS, Raza AA. Sustainable IVR-Based Social Media for the Developing World. 
25. Briggs P, Blythe M, Vines J, Lindsay S, Dunphy P, Nicholson J, Green D, Kitson J, Monk A, Olivier P. Invisible design: exploring insights and ideas through ambiguous film scenarios. InProceedings of the Designing Interactive Systems Conference 2012 Jun 11 (pp. 534543). ACM.

26. Vashistha A, Cutrell E, Borriello G, Thies W. Sangeet swara: A community-moderated voice forum in rural india. InProceedings of the 33rd Annual ACM Conference on Human Factors in Computing Systems 2015 Apr 18 (pp. 417-426). ACM.

27. Mudliar P, Donner J, Thies W. Emergent practices around CGNet Swara: A voice forum for citizen journalism in rural India. Information Technologies \& International Development. 2013 Jun 10;9(2):pp-65.

28. Gram Vaani. Last Accessed 18th Sep 2018 from http://gramvaani.org/.

29. Kazakos K, Asthana S, Balaam M, Duggal M, Holden A, Jamir L, Kannuri NK, Kumar S, Manindla AR, Manikam SA, Murthy GV. A real-time ivr platform for community radio. In Proceedings of the 2016 CHI Conference on Human Factors in Computing Systems 2016 May 7 (pp. 343-354). ACM.

30. Patel N, Chittamuru D, Jain A, Dave P, Parikh TS. Avaaj otalo: a field study of an interactive voice forum for small farmers in rural india. In Proceedings of the SIGCHI Conference on Human Factors in Computing Systems 2010 Apr 10 (pp. 733-742). ACM.

31. Grover AS, Plauché M, Barnard E, Kuun C. HIV health information access using spoken dialogue systems: Touchtone vs. speech. In Information and Communication Technologies and Development (ICTD), 2009 International Conference on 2009 Apr 17 (pp. 95-107). IEEE.

32. Mamykina L, Mynatt E, Davidson P, Greenblatt D. MAHI: investigation of social scaffolding for reflective thinking in diabetes management. In Proceedings of the SIGCHI Conference on Human Factors in Computing Systems 2008 Apr 6 (pp. 477-486). ACM.

33. Yang Y, Liu C, Li C, Hu Y, Niu Y, Li L. The recommendation systems for smart tv. In Computing, communication and networking technologies (ICCCNT), 2014 international conference on 2014 Jul 11 (pp. 1-6). IEEE.

34. Gardner-Bonneau D. Guidelines for speech-enabled IVR application design. In Human factors and voice interactive systems 1999 (pp. 147-162). Springer, Boston, MA.

35. Sherwani J, Ali N, Mirza S, Fatma A, Memon Y, Karim M, Tongia R, Rosenfeld R. Healthline: Speech-based access to health information by low-literate users. In Information and Communication Technologies and Development, 2007. ICTD 2007. International Conference on 2007 Dec 15 (pp. 1-9). IEEE.

36. Korpela M, Soriyan HA, Olufokunbi KC. Activity analysis as a method for information systems development. Scandinavian Journal of Information Systems. 2001 Jan 1;12(12):191-210.

37. Chib A. Research on the impact of the information society in the global south: an introduction to SIRCA. In Impact of Information Society Research in the Global South 2015 (pp. 117). Springer, Singapore.

38. Bowen S, Dearden A, Wright P, Wolstenholme D, Cobb M. Participatory healthcare service design and innovation. In Proceedings of the 11th Biennial Participatory Design Conference 2010 Nov 29 (pp. 155-158). ACM.

39. Jones, M., Robinson, S., Pearson, J., Joshi, M., Raju, D., Mbogo, C.C., Wangari, S., Joshi, A., Cutrell, E. and Harper, R., 2017. Beyond yesterday's tomorrow: future-focused mobile interaction design by and for emergent users. Personal and Ubiquitous Computing, 21(1), pp.157-171. 
40. Haque, M.M., Kawsar, F., Adibuzzaman, M., Uddin, M.M., Ahamed, S.I., Love, R., Hasan, R., Dowla, R., Ferdousy, T. and Salim, R., 2015. e-ESAS: Evolution of a participatory design-based solution for breast cancer (BC) patients in rural Bangladesh. Personal and Ubiquitous Computing, 19(2), pp.395-413.

41. Medhi-Thies, I., Ferreira, P., Gupta, N., O'Neill, J. and Cutrell, E., 2015, February. KrishiPustak: a social networking system for low-literate farmers. In Proceedings of the 18th ACM Conference on Computer Supported Cooperative Work \& Social Computing (pp. 1670-1681). ACM.

42. Ahmed, F., Asim-Bin-Zafar, M.R., Ghafoor, E., Rehman, R.A. and Uddin, Q., 2017. Impact of 24-hour helpline service for people with diabetes. Pakistan journal of medical sciences, 33(3), p.747.

43. Yadav, D., Singh, P., Montague, K., Kumar, V., Sood, D., Balaam, M., Sharma, D., Duggal, M., Bartindale, T., Varghese, D. and Olivier, P., 2017, April. Sangoshthi: Empowering Community Health Workers through Peer Learning in Rural India. In Proceedings of the 26th International Conference on World Wide Web (pp. 499-508). International World Wide Web Conferences Steering Committee. 